\title{
Participación Ciudadana: Significados y Sentidos Atribuidos por Actores Sociales a Partir de la Gestión Pública de Dos Agentes Educativos Municipales
}

\author{
Citizen Participation: Meanings and Senses Attributed by Social \\ Actors since the Public Management of Two Municipal \\ Educational Agents
}

\section{Participação Cidadã: Significados e Sentidos Atribuídos pelos Atores Sociais a partir da Gestão Pública de Dois Agentes Municipais de Ensino}

Judith Rojas de Lúquez ${ }^{1 *}$ Belkis Ballester Pérez ${ }^{2}$

\footnotetext{
${ }^{1}$ Universidad Nacional Experimental Rafael María Baralt

${ }^{2}$ Universidad Nacional Experimental Simón Rodríguez
}

\begin{abstract}
El objetivo de la investigación fue caracterizar la participación ciudadana y develar el significado y sentido que le atribuyen los actores sociales, a través de las prácticas de gestión desarrolladas por dos agentes educativos que, de manera latente, conforman una mancomunidad educativa. Los escenarios de investigación fueron un Concejo Municipal y dos escuelas, los tres ubicados en un mismo espacio local. Metodológicamente, utilizamos estrategias empírico-hermenéuticas de la Teoría Fundamentada, realizando análisis comparativos y continuos de la información proveniente de observaciones participantes y de entrevistas a profundidad a informantes clave. Los hallazgos develan que ambas instituciones son escenarios de participación simulada que replican la cultura política tradicional.
\end{abstract}

Descriptores: Participación ciudadana, Gestión pública, Agentes educativos, Educación informal, Teoría fundamentada.

\begin{abstract}
The research objective was characterizing the citizen participation and uncovering its meaning and sense attributed for social actors, through the management practices developed by two institutional agents that, in a latent way, make up an educational commonwealth. The scenes of research were one City Council and two schools, all three situated in the same local space. Methodologically, we used empiricalhermeneutics strategies of Grounded Theory, carrying out continuous and comparative analysis of information from participating observations and in-depth interviews with key informants. The findings reveal that both institutions are scenes of simulated participation which replicate the traditional political culture.
\end{abstract}

Keywords: Citizen participation, Public management, Educational agents, Informal education, Grounded theory.

*Contacto: judithdlu@hotmail.com 
O objetivo do trabalho foi caracterizar a participação cidadã e revelar o significado de sentido que lhe é dado pelas partes interessadas, através de práticas de gestão desenvolvidas por dois agentes educativos de forma latente, formar uma associação educacional. Os cenários da pesquisa foram um Conselho Municipal e duas escolas, três localizados no mesmo espaço local. Metodologicamente, usamos estratégias hermenêuticas empíricos da Grounded Theory, realizando análises comparativas e informação contínua a partir de observação e de entrevistas participante com informantes-chave. Os resultados revelam que as duas instituições são cenários simulados de participação que replica a cultura política tradicional.

Palavras-chave: Participação cidadã, Gestão pública, Agentes educativos, Informal educação, Grounded theory.

\section{Introducción}

La participación ciudadana es el núcleo de la democracia al constituir la posibilidad efectiva de interacción de la sociedad con el Estado. Ello requiere que las organizaciones públicas dediquen tiempo y esfuerzo a fortalecer la implicación de los sujetos sociales en los asuntos de interés colectivo.

En Venezuela, a partir de 1999, existe un marco jurídico en el que la participación ciudadana en la gestión pública es un mandato y orienta su organización en diversas formas institucionales que pueden calificarse de amplísimas y hasta suficientes. Sin embargo, ello no basta para que la gente se empodere de su ciudadanía. Persisten patrones de comportamiento individualistas que requieren ser desplazados por otros de profunda valoración del bien común.

Esta situación refleja que una participación ciudadana efectiva, orientada hacia el desarrollo del modelo político, social y económico consagrado en la Constitución venezolana, para efectos de la consolidación de la democracia participativa y protagónica instituida, está condicionada por la construcción de una gestión educativa socialmente integral que procure la formación de los individuos a través de experiencias, vivencias y realidades vinculadas a un sistema de relaciones de los individuos con el Estado en calidad de ciudadanos.

Lo anterior implica articular las organizaciones públicas como agentes que pueden formar mancomunadamente en el ejercicio de la ciudadanía, de forma tal que en la gestión de lo público se tomen decisiones consensuadas de acuerdo al derecho de los sujetos y de las comunidades organizadas a intervenir en procura de hacer más efectiva la actuación del Estado. Estamos haciendo referencia a una nueva cultura política gestada institucionalmente que promueva y modele la construcción de significados, sentidos y valores ciudadanos atinentes a nuestra Constitución.

Así, se apunta a una nueva ética en la función pública que se oriente a un desarrollo político, social y económico con equidad y justicia, como señala Fuenmayor (2006), que venza las barreras de la profunda disociación entre el discurso y la práctica en la gestión pública, sobre lo que abundan los ejemplos en las instituciones venezolanas.

A tales efectos, coincidimos con Barrera (2004) cuando señala que lo local aparece como el ámbito privilegiado para construir este tipo de experiencias por las implicaciones político-institucionales y, sobre todo, socio-culturales derivadas de la escala demográfica y de los sentidos de identidad y pertenencia. 
En esta perspectiva, el municipio se convierte en un espacio idóneo de aprendizaje ciudadano pues los actores sociales, participando en la gestión pública de instituciones que les son cercanas, conocen y comprenden sus derechos y obligaciones, amplían un sentimiento de pertenencia e inclusión, toman responsabilidad al buscar el beneficio comunitario y se habitúan con la institucionalidad del Estado.

De allí la prioridad dada en nuestra investigación a agentes institucionales que comparten un mismo espacio local, conminados a integrar en su gestión la participación ciudadana, promoviendo y modelando acciones que la favorezcan como ejercicio activo en su propia dinámica cotidiana, en atención permanente a sus deberes y responsabilidades públicas. Se trata de formación de ciudadanía desde la práctica de gestión institucional.

Nos situamos así en la educación informal (García y García, 1996), que hace referencia a los procesos permanentes de aprendizaje que toda persona vive en sus relaciones sociales así como en sus prácticas cotidianas, que fomentan mecanismos primarios de formación tales como la imitación y la reproducción de comportamientos y contenidos lingüísticos. Y lo hacemos desde una perspectiva sociopolítica que nos invita a interpretar la formación de ciudadanía en el contexto del sistema de las relaciones de poder en que transcurre.

Bajo tales consideraciones, en este artículo presentamos los resultados parciales de una investigación amplia orientada a interpretar la formación de ciudadanía que, desde la promulgación de una nueva Carta Magna, opera en Venezuela en ámbitos de educación informal, es decir, distintos al aula de clases.

Específicamente, nos planteamos comunicar los atributos de la participación ciudadana en una localidad del occidente de Venezuela y los significados construidos y sentidos que le atribuyen los actores sociales, a partir de las prácticas de participación que ofrecen y demandan dos agentes institucionales ubicados en un mismo espacio local, que potencialmente conforman una mancomunidad educativa.

La prioridad dada a los significados y sentidos se basa en la premisa de que para comprender una realidad social particular es imprescindible captar el sentido que la acción tiene para los actores e interpretar lo que explican o relatan, los significados, lo simbólico, sus creencias, valores, actitudes, elementos que juntos operan como sistemas de referencias subyacentes en cada uno de sus comportamientos. El sentido de la acción social para Weber (1973) "es aquella comprensible, comunicable adecuadamente por medio de la palabra a través de la cual se puede revivir a plenitud los hechos de la experiencia de los actores sociales" (p. 5).

\section{Sobre la participación ciudadana}

La participación ciudadana inscrita en una concepción de democracia participativa debe ser significativa y auténtica, involucrar a todos los sujetos, estableciendo diferencias pero engranando sus roles, y darse en variados ámbitos y dimensiones.

Ello demanda que los actores sociales deben ser formados y auto-formarse para la participación social, comunitaria y política, lo que daría lugar al nacimiento de una cultura participativa que guíe a la internalización de deberes y derechos ciudadanos, que valore la necesidad de la participación para el mantenimiento y funcionamiento del sistema democrático y que muestre en la práctica los beneficios que su ejercicio aporta para nuestro propio bienestar y perfeccionamiento humano. 
En efecto, con un sentido eminentemente social que se enuncia en la Constitución de la República Bolivariana de Venezuela (CRBV, 1999), se esbozan las pautas de comportamiento hacia la participación ciudadana en los asuntos públicos, así como también lo relacionado a las fases en las cuales dicha participación se hace efectiva como expresión del carácter protagónico del ejercicio político:

Todos los ciudadanos y ciudadanas tienen el derecho de participar libremente en los asuntos públicos, directamente o por medio de sus representantes elegidos o elegidas. La participación del pueblo en la formulación, ejecución y control de la gestión pública es el medio necesario para lograr el protagonismo que garantice su completo desarrollo, tanto individual como colectivo. Es obligación del Estado y deber de la sociedad facilitar la generación de las condiciones más favorables para su práctica. (Artículo 62)

Es decir, el ciudadano y la ciudadana ya no serían simples electores sino que pasarían a ser sujetos activos en la toma de decisiones públicas, con la idea de hacer más efectiva, eficaz y eficiente la gestión del Estado. La acción participativa adquiere rango constitucional y esto quiere decir que la participación ciudadana es de naturaleza vinculante, de obligatorio cumplimiento por todos los actores.

Se trata del desarrollo de una cultura participativa en la gestión pública que ha de expresarse como una acción que concientiza y socializa a quienes se involucran en ella, mediante la identificación del sujeto como actor importante para la satisfacción de las necesidades colectivas, propiciando un mayor involucramiento directo de la población en los procesos decisorios de las organizaciones que afectan sus vidas pero sin pretender que los ciudadanos asuman las acciones que compete desarrollar al gobierno en funciones de Estado.

Por mandato constitucional, toda gestión pública ha de ser participativa. No obstante, el discurso sobre la participación ciudadana, sobre lo político y sobre la democracia, se contradice con la realidad de las prácticas sociales y de las instituciones que en mención a las mismas llevan a cabo procesos y actividades que por lo general, terminan siendo poco democráticas y limitadas de participación ciudadana.

Así, al fragor de procesos eleccionarios y de resguardo de los poderes políticos constituidos, se vacía de contenido sustantivo a la democracia participativa y la pretendida participación ciudadana en la gestión pública venezolana actualmente no va más allá de un enfoque puramente instrumental.

Porque no basta la consagración constitucional del cambio de democracia representativa por la participativa y protagónica, que incluye mecanismos de participación ciudadana, para corregir los hábitos heredados de una cultura política orientada por un modelo de relaciones verticales Estado-sociedad. La voluntad política requerida para transformar esa cultura pareciera no manifestarse seriamente en las experiencias que estamos viviendo en la actualidad.

Se requiere entonces formación de ciudadanía y desarrollo de una cultura participativa, un cambio en las concepciones y prácticas volitivas de la gente, y para ello hemos de partir de una seria reflexión sobre el hacer de los agentes educativos. Porque la educación tiene que asumir un rol protagónico en su máximo objetivo de desarrollo humano, en su condición política para el aprendizaje de ciudadanía, por cuanto debe existir un espacio en común en el cual se vivencie el sentido de lo democrático (Beltrán, 1998). 
Ballester (2006) destaca que el aprendizaje de la ciudadanía es la participación y añade que, además de la escuela, otros espacios de educación, no formales e informales, toman parte en la formación de ciudadanía, donde en situaciones cotidianas de interacción social se aprende haciendo: se aprende a participar participando. Folgueiras (2005) amplía esta concepción cuando afirma que la ciudadanía es un proceso interactivo donde tanto unos como otros aprenden conocimientos y destrezas que benefician al proyecto que desarrollan, que no se vincula exclusivamente con la adquisición legal de un estatus sino con el desarrollo de un sentido de pertenencia a una comunidad política, que lleva a la ciudadanía a participar en los asuntos públicos y a adquirir las competencias ciudadanas necesarias para tener presencia activa en el espacio público asumido con responsabilidad.

En ese sentido, De Alba, García y Santisteban (2012) destacan que son muchas las investigaciones y las propuestas educativas innovadoras que reclaman una nueva educación política o educación cívica que ponga el acento en la participación, que se sitúan tanto en la educación formal como en la no formal, tanto en diferentes ámbitos institucionales como por parte de distintas entidades no gubernamentales.

De allí que entendamos que todas las instituciones sociales y organizaciones de todo tipo que conforman la sociedad son espacios educativos. En otras palabras, son educadoras y, en este sentido, todos somos actores y agentes educativos en la medida en que al relacionamos unos con otros, de un modo o de otro, mediamos el aprendizaje de esos otros, tanto como ellos los nuestros. Por ejemplo, en esas relaciones trasmitimos valores y actitudes a través de nuestras formas de hacer y de decir.

Lo anterior implica que lo educativo tiene lugar aun cuando no tengamos una intencionalidad explícita, lo que, sin embargo, no quiere decir que todos seamos agentes del mismo tipo, pues se puede diferenciar entre actores escolares y no escolares, o entre espacios relacionales formales o informales, o entre grupos de mayor o menor proximidad relacional en la dinámica cotidiana. Lo educativo puede suceder siempre por cuanto no llevamos una vida aislada, lo que en alguna medida conduce a la construcción social de la realidad.

Por ello se afirma que las ciudades son espacios educativos (Cabezudo, 2006; Carranza, Garriga y Llinás, 2011; Rebollo, 2004; Roser, 2006) pero se clama que la ciudad tiene que transformarse de un simple escenario de intervención educativa a un agente educativo que incida activamente en la educación de sus ciudadanos. En la misma línea de ciudad educadora, Coma (2011) apunta la idea de que para educar a las personas no basta con la familia y la escuela, sino que la responsabilidad de formar es de toda la sociedad y, por lo tanto, de todos aquellos que compartimos un espacio de convivencia común denominado ciudad. Se trata de una decidida apuesta por la recuperación de la fuerza social ciudadana, de manera que exige la integración de todas y cada una de las instituciones, asociaciones y colectivos de la ciudad.

Igualmente, Roser (ob. cit.) recalca que el concepto educación sobrepasa la escuela, tanto en lo referente al espacio, con una multiplicidad de agentes socializadores, y como un proceso permanente, a lo largo de nuestra vida. El marco socializador de la actividad educativa pasa a ser el entorno en su sentido más amplio (ciudad, medios de comunicación, relaciones sociales), lo que comprende todas las tipologías educativas: formal, no formal e informal. 
Dentro del conglomerado de agentes educativos, en nuestra investigación distinguimos primordialmente dos para efectos del aprendizaje de la participación ciudadana a nivel local: el Concejo Municipal y la escuela, que dan lugar a la trama en la gestión pública que nos ocupa y se caracterizan por ser instituciones donde se desenvuelven actores comunes a ambas.

Por ello, es pertinente abordar la premisa de la dimensión mancomunidad conformada por la asociación de estos dos agentes educativos como elemento de un proceso educativo permanente y de construcción de una cultura política en la que estos agentes, en ejercicio activo de sus deberes y responsabilidades sociopolíticas, coadyuven al proceso de formación de ciudadanía democrática.

En definitiva, tal mancomunidad constituye un excelente observatorio para una concreta comprensión de las formas que toma la participación ciudadana, toda vez que los proyectos de ordenanza del Concejo Municipal deben ser sometidos a consulta pública y la escuela lleva implícita la participación en su gestión pedagógica y, al menos formalmente, en su gestión administrativa.

\section{La estrategia metodológica}

Para caracterizar e interpretar el significado y el sentido de la participación ciudadana a nivel local, en la investigación seguimos las estrategias ofrecidas por Glasser y Strauss (1967) para generar Teoría Fundamentada: la comparación continua de los datos y el muestreo teórico, apoyándonos además en herramientas analíticas propuestas por Strauss y Corbin (2002) y en la matriz de relaciones condicionales-consecuenciales diseñada por Wilson y Howell (2008).

La investigación transcurrió en el contexto de la ciudad de Carora, Venezuela, entre los años 2010 y 2013, en tres organizaciones públicas: el Concejo Municipal, una escuela A de educación primaria y otra $\mathrm{B}$ de educación media, que comparten el mismo espacio geográfico local y, entre sus actores, la mayoría mantiene relaciones con al menos dos de ellas y, en algunos casos, con las tres. La técnica inicial empleada para aprehender la participación de actores individuales y grupales en la gestión institucional fue la observación participante de eventos legislativos y escolares relevantes. Los momentos de observación fueron de dos tipos: por una parte, los definidos de acuerdo a las programaciones anuales de las instituciones, tales como las consultas públicas de ordenanzas de acuerdo a la agenda legislativa del Concejo Municipal, la elección de autoridades educativas y asambleas escolares; por otro, eventos no programados que surgieron de la propia dinámica de las instituciones mientras permanecíamos en ellas.

Todos los eventos observados fueron registrados durante el primer año de la indagación en los escenarios cotidianos de interacción organizacional: el salón de sesiones del Concejo Municipal, la Unidad de Atención Ciudadana y, al interior de las escuelas, en los patios, pasillos y oficinas administrativas. Entre un evento observado y otro transcurrió de un mes a mes y medio, tiempo requerido para ordenar y transcribir las notas de campo y los audios capturados, así como analizar las fotografías tomadas para luego someter esa data a micro-análisis, en un proceso de codificación abierta, comparación de incidentes y códigos, y su consiguiente agrupación y reagrupación para construir categorías preliminares. 
Las interrogantes “QQué es la participación?”, “En qué se participa?”, ¿Cómo se participa?”, “Quiénes participan?” y “¿Para qué participan?” se utilizaron como herramienta analítica y de comparación teórica para guiar la selección sistemática de los incidentes y maximizar el surgimiento de códigos y categorías preliminares. Estas últimas constituyeron las pistas para el muestreo teórico realizado a través de entrevistas a profundidad. Así, como segunda técnica empleada, las entrevistas a informantes clave permitieron profundizar en las categorías iniciales. En los encuentros, los versionantes expresaron libremente opiniones y sentimientos acerca del tema en estudio, posibilitando descifrar significados subyacentes en sus pensamientos, pero develados en sus discursos. En total se realizaron ocho entrevistas a profundidad a cinco actores, tres de ellos hombres y dos mujeres.

De los hombres, uno se desempeñaba como presidente de la comunidad educativa de la escuela B y como funcionario del Concejo Municipal, otro era un estudiante de la tercera edad de la Misión Robinson (alfabetización) que se desarrolla en la escuela A, usuario asiduo de los servicios del Concejo Municipal y el otro, un vocero de un Consejo Comunal de una zona aledaña a las instituciones asociadas al estudio, representante de un estudiante de la escuela A y también consuetudinario visitante del Consejo Municipal. De las mujeres, una era vocera de otro Concejo Comunal cercano y enlace de estas instancias de organización comunitaria con la Alcaldía, mientras las otras dos eran docentes, la una de la escuela A y la otra de la escuela B, ambas habitantes del mismo sector donde se ubican las instituciones en cuestión.

Los diálogos con los informantes fueron grabados en audio y posteriormente se procedió a su transcripción fiel y a sus respectivos microanálisis, codificación y comparación de incidentes y códigos para la generación de categorías preliminares, lo que podemos decir constituyó la segunda parte de la primera fase analítica o codificación abierta. Como resultado de esta fase se generaron 86 códigos que fueron asociados a 39 categorías preliminares.

La segunda fase analítica la constituyó la comparación y reducción de códigos y categorías en virtud de sus vínculos semánticos, resultando en ocho (8) categorías emergentes, germinadas de la hibridación de códigos, en un proceso de codificación axial apoyada por la matriz de relaciones condicionales-consecuenciales, que proveyó la guía para interrelacionar categorías emergentes, subcategorías y propiedades. En la matriz, se organizaron las categorías en el eje vertical y los códigos, en cinco columnas horizontales que responden a: ¿qué es?, ¿cuándo ocurre?, ¿dónde ocurre?, ¿cómo ocurre?, ¿por qué ocurre? y, por último, ¿cuáles son las consecuencias? Su operatividad posibilitó una visión de lo complejo del fenómeno en estudio al responder tanto a su estructura y proceso como a sus consecuencias. Con ella se develaron relaciones intercategoriales, que obligaron a regresar al campo para saturar la información y densificar las categorías.

En la última fase analítica o codificación selectiva, dada la convergencia y divergencia trascendida de los análisis comparativos continuos y del muestreo teórico, obtuvimos tejidos conceptuales derivados de la afinidad intercategorial que permitió resignificar las categorías en cuatro densas: Partidización de la Gestión, Convivencia Conflictiva, Ciudadanía Clientelizada y Participación Simulada — esta última objeto de la presente comunicación- y seleccionar la primera como central, dado su alcance analítico para integrar e interrelacionar las categorías en un todo, facilitando una comprensión e 
interpretación de la participación ciudadana bajo la gestión de dos agentes educativos en el escenario del estudio.

\section{Los hallazgos y su interpretación}

En el transitar metodológico sucintamente descrito, caracterizamos la participación ciudadana en la gestión de las instituciones públicas focalizadas y develamos los significados que sobre ella han construido y los sentidos que le atribuyen los actores sociales.

\subsection{Caracterización de la participación ciudadana}

Encontramos que, al interior de las instituciones observadas, la participación ciudadana es simulada, lo que alude a las posibilidades de falsear la participación y se reduce a recibir información y a aprobar lo ya decidido. Se trata de una participación instrumentada como vía de control social, de legitimación política y de eficacia para los intereses dominantes de los actores que ocupan cargos de jerarquía en las instituciones.

En la Participación Simulada se distinguen cuatro (4) subcategorías: la Participación Clientelar, la Participación Ornamental, la Participación Simbólica y la Participación Real Aparente, tal como se presenta en la figura 1.

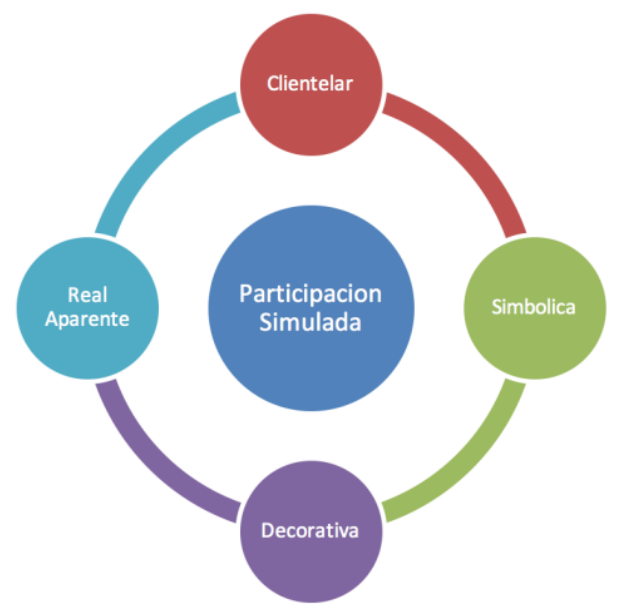

Figura 1. Participación simulada

Fuente: Elaboración propia.

La Participación Clientelar pudo ser develada en el discurso de los actores sociales como el instrumento al servicio de los intereses de la autoridad que se mantiene en el cargo por el agradecimiento que le brindan quienes reciben algún beneficio:

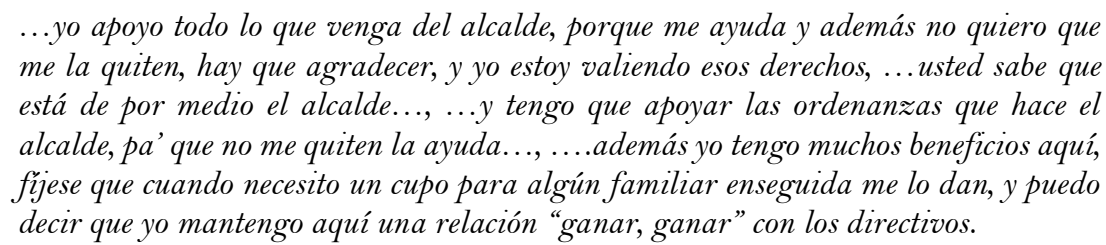

Es una participación que se despliega por un vínculo clientelar entre las autoridades que ocupan cargos públicos en busca de apoyo político para continuar en el cargo y los actores sociales, quienes se sienten agradecidos por los beneficios recibidos y motivados por el 
interés personal de mantenerlos o recibir otros. En tal escenario, la participación clientelar es una relación de intercambio voluntario entre actores en la que ambas partes buscan obtener ventajas de la acción. Está marcada por una lógica de entrega de bienes o servicios a cambio de apoyo o lealtad política.

En términos generales, la participación clientelar es un simulacro de participación porque niega el proceso educativo a través del cual los actores sociales toman conciencia de las situaciones tanto particulares como colectivas que los afectan y deciden actuar en conjunto para modificarlas. En la participación clientelar que se manifiesta en la actuación de los dos agentes educativos estudiados se identifican dos dimensiones: la participación clientelar coaccionada y la participación clientelar condicionada.

La participación clientelar coaccionada refiere al hecho de que los actores sociales, por miedo, prefieren callar y no sufrir las consecuencias de perder beneficios si no dan su apoyo:

... y preferimos callar, porque no quiero ni pensar en las consecuencias si insistimos y llevamos la contraria. Claro está ellos siempre tienen la aprobación porque tienen la mayoría.

Los actores sociales asisten a los llamados a participar o apoyan sin objetar las ideas y actuaciones de las autoridades haciéndose copartícipes de unas prácticas de sumisión, vulnerándose así la genuina participación, por cuanto queda relegada a las decisiones de la autoridad, quien se apoya en una comunicación mediática y hace entender a los actores sociales que si no hay apoyo no podrán mantener los beneficios que ya tienen:

$$
\begin{aligned}
& \text {.. y además nosotros con solamente decirles que deben cuidar el cupo de sus } \\
& \text { representados apoyándonos sin causar problemas, ellos toman la onda y la siguen... } \\
& \text { Si a veces los hay [quien se oponga], pero no le prestamos atención porque siempre la } \\
& \text { gran mayoría está de nuestro lado y ellos saben que el perjudicado a la final es el } \\
& \text { muchacho, y no les queda más que aceptar lo que hacemos, así de fácil. }
\end{aligned}
$$

Por su parte, la participación clientelar condicionada es referida al hecho de que los actores sociales, por la aspiración de obtener beneficios como viviendas, becas, incluso hasta comida, se movilizan a los eventos destinados como participativos previstos tanto por el Concejo Municipal como por la escuela. Los actores acuden a estos eventos atendiendo a los ofrecimientos de la autoridad a cambio de apoyo incondicional a la gestión a través de firmas y lealtad política al gobierno que desarrollan:

$$
\begin{aligned}
& \text {...claro está que si vienen a darnos beneficios como por ejemplo las casas para allá } \\
& \text { vamos todos... mandaron a decir que fuéramos para la asamblea y mi compadre nos } \\
& \text { reunió a todos que nos iban a dar las casas pa' los muchachos, pa' los hijos nuestros } \\
& \text { que viven arrimaos con uno y por eso fuimos, por las casas. }
\end{aligned}
$$

En otros testimonios se señala:

$$
\begin{aligned}
& \text {...bueno, aqui estamos apoyando a la directora, ella es la mejor, fijese que cuando } \\
& \text { hubieron las inundaciones ella estaba metida en el agua llevando bolsas de comida y } \\
& \text { las otras maestras ni se asomaron y además nos trata bien y de aquí no la saca nadie. } \\
& \text { ro que me la paso en el comedor de la escuela puedo dar fe de ello y nos da comida } \\
& \text { cuando estamos en el comedor también. ¿Qué otra directora va hacer eso con nosotros } \\
& \text { de darnos comida? Por eso ella tiene todo nuestro apoyo incondicional..., Sí, porque } \\
& \text { tú sabes que yo vengo a la alcaldía mensual a buscar ayuda o cuando hay runrunes de } \\
& \text { pago de la beca. }
\end{aligned}
$$

Estos hallazgos coinciden con los obtenidos por Landini (2012) al estudiar las prácticas políticas en una localidad campesina de Argentina, donde son las ayudas públicas el medio más importante para la construcción de legitimidad y consenso, tanto en momentos 
electorales como a lo largo del tiempo. Así, señala que no se intercambia el voto por bienes, sino que se lo da como forma de reconocer la ayuda recibida o de mantener el flujo de ayudas en el tiempo, lo cual puede estar mediado por sentimientos de lealtad personal o de gratitud hacia ciertos dirigentes por los favores que han brindado.

Audelo (2004) define al clientelismo como aquellas relaciones informales de intercambio recíproco y mutuamente benéfico de favores entre dos sujetos, basadas en una amistad instrumental, desigualdad, diferencia de poder y control de recursos, en las que existe un patrón y un cliente: el patrón proporciona bienes materiales, protección y acceso a recursos diversos y el cliente ofrece a cambio servicios personales, lealtad, apoyo político o votos.

De acuerdo al mismo autor, los comportamientos clientelares son frecuentes en los análisis y estudios sobre los problemas políticos y sociales de algunos países en vías de consolidación democrática. Así encontramos que Cernadas, Pineda y Chao (2013), a partir de comparar la participación ciudadana en Galicia y La Rioja, manifiestan preocupación porque, en algunos casos, la participación es entendida como el contacto individual de los vecinos con los miembros del gobierno municipal, lo que puede estar indicando un cierto comportamiento clientelar.

Se trata de una relación política, porque no es exclusivamente económica o de amistad, ni tampoco de solidaridad. Reporta o mantiene un beneficio, no necesariamente cuantificable, a partir de un intercambio directo e indirecto que se produce en el ámbito de lo público pero que responde a mecanismos propios del mercado (Günes-Ayata, 1994). Es decir, se da un intercambio extrínseco entre la autoridad y los actores sociales, en donde ambas partes se benefician, a pesar de su situación de desigualdad funcional que, sin embargo, no afecta al intercambio que las partes requieren para alcanzar sus fines.

La Participación Decorativa opera cuando las autoridades, tanto del Concejo Municipal como de la escuela, incorporan a los actores sociales a las actividades de consulta pública de las ordenanzas o a las asambleas escolares, como lo expresan los propios actores "a hacer bulto". Los actores sociales acuden al llamado a través de convocatorias e invitaciones pero desconocen a qué van:

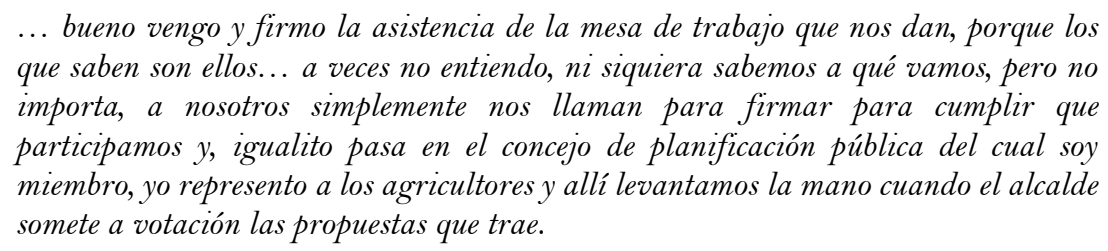

En la Participación Decorativa se distinguen dos dimensiones: consultiva e informativa, dependiendo de si en lo que se participa refiere a una acción futura o pasada. Pero en ambos casos el único propósito que mueve a los agentes educativos a realizar los llamados a la participación es cumplir con el requisito de ley de aprobación pública de, en el Concejo Municipal, los proyectos de ordenanza propuestos generalmente por la Alcaldía, pero podría ser por otro organismo, por ejemplo, un consejo comunal: “....y usted sabe hay que cumplir con el requisito de la ley. Si no se mete a consulta no pueden ustedes aprobarla”.

Y en la escuela, los directivos en condición de encargados solo son ratificados si la comunidad educativa aprueba sus informes de gestión directiva del año escolar que culmina:

...la directora actual tiene que presentar un informe de gestión que tiene que estar avalado por la comunidad en asamblea, para poder ser ratificada en el cargo profe, y 
ya la directora se fue casa en casa para que lo firmen cuando ni siquiera lo ha presentado en la asamblea.

También requieren ratificación pública las autoridades que quedan electas, en caso de vacantes, por el comité escolar de sustanciación de credenciales: “....asistir a las convocatorias y apoyar a los profesores... mi participación es apoyar a los profesores que quedaron".

En tales situaciones, las autoridades restan importancia a la participación masiva o no de actores sociales y aprovechan la pasividad de aquellos para imponer sus decisiones, las cuales son aceptadas sin objeción alguna. Para ambas instituciones lo primordial es cumplir con la norma y la participación auténtica de los actores sociales pasa a ocupar un segundo plano.

Así, en el Concejo Municipal, hacer una consulta pública es sinónimo de que asistan unos pocos y, en la escuela, es sinónimo de firmas, las cuales recogen en el mismo momento de la actividad y completan los formatos tomando las de los no asistentes posteriormente: “...porque los que no asistan tienen que pasar por la seccional que le corresponde a firmar la planilla. Si porque las firmas es avalando la información suministrada por nosotros" o, en el caso extremo, obtienen las firmas con anterioridad: "y ya la directora se fue casa en casa para que lo firmen cuando ni siquiera lo ha presentado en la asamblea".

Es decir, se simula un ambiente participativo con la asistencia de los actores sociales invitados a través de la prensa local o de sendos paleógrafos publicados en las puertas de la institución para hacerlos públicos y notorios, y muchos asistentes tienen la ilusión de estar participando.

Estos hallazgos contrastan con los reportados por Pino y Colino (2007), quienes al analizar comparativamente las iniciativas de promoción de la participación ciudadana en los gobiernos locales de cuatro países europeos, encontraron que en el Reino Unido ha habido un crecimiento significativo de los métodos consultivos y deliberativos debido a que "las autoridades públicas buscan un enfoque pro-activo de la participación. En estos casos, las decisiones no suelen estar preconcebidas y se incorpora a los ciudadanos en una etapa inicial del proceso de adopción de decisiones" (pp. 15-16).

No obstante, Román (2012) critica que, a pesar de que en algunos países de la Unión Europea se está dando marcha atrás en la ejecución de medidas asociadas a la Nueva Gestión Pública y encontrándose vigente el nuevo paradigma de la gobernanza, el ciudadano sigue apareciendo en los documentos oficiales de reforma como "ese cliente de la administración cuyas necesidades hay que 'satisfacer', y esto a pesar de que tal consideración contradice abiertamente los principios que inspiran las características del llamado gobierno relacional" (p. 82).

Por su parte, la Participación Simbólica se gesta en los propios actores sociales cuando renuncian a su derecho constitucional a intervenir en el proceso de gestión pública y se conforman con figurar en una solicitud colectiva o en unas elecciones. Así, la participación simbólica se manifiesta en dos dimensiones: representativa y eleccionaria.

La representativa tiene lugar cuando los actores sociales dejan a un lado la oportunidad de intervenir directamente en la toma de decisiones colectivas por cuanto se les demanda que su participación sea a través de los grupos organizados. Es decir, si desean hacer algún reclamo o propuesta ante la institución, deben utilizar la figura de los concejos comunales: 
...todo en estos momentos... debe ser como comunidad organizada, o sea, exigen una representación de nosotros... Como te explicara, tenemos el problema y uno... este... uno va agarrando conciencia, porque a nosotros mismos... a la gente, a la comunidad..., a las personas no nos interesa participar, pero tenemos la gente que son los voceros y ellos nos representan y hacen las reuniones y nos dicen lo que han hecho.

En otros testimonios se señala:

...pero para poder ir a las oficinas de los institutos, a las instituciones y que nos atiendan tiene que ser una representación de nosotros mismos en organización comunitaria, no puedo ir sola, tiene que ser como asociación de vecinos, junta comunal asi lleve cualquier nombre pero debe ser en organización de nosotros mismos, y nosotros tenemos nuestro consejo comunal y además a través de ello dice el gobierno es que vamos a conseguir beneficios.

Por su parte, la eleccionaria se muestra cuando los actores sociales asumen que:

...Bueno, participación es votar... y aquí se hace a cada rato, es más desde que Chávez llegó al gobierno han ocurrido trece elecciones y yo he votado en todas y eso gracias a la participación que es lo más grande que tiene la democracia. Porque yo voto y eso es democracia y eso para mí es participación, porque si tú vives en democracia ejerces tus derechos y te lo demuestro votando así sea con disimulo.

La participación simbólica muestra que las posibilidades reales de participación que ofrecen las instituciones públicas estudiadas en la actualidad están todavía amalgamadas con la representación. Y en este escenario, se fortalecen patrones de conducta, creencias, visiones y prácticas participativas que debilitan la ejecución de acciones que, en lo concreto, se enmarcan en el protagonismo.

La dimensión representativa de la participación simbólica ha sido evidenciada en otros estudios. Por ejemplo, González (2011) al comparar la participación ciudadana entre las ciudades de Madrid y Helsinki, encontró que la participación realmente se encontraría supeditada a un sistema de representación y delegación de las decisiones, en el cual deciden, en gran medida, los representantes integrados a organizaciones partidistas. Y como señalan Pino y Colino (ob. cit.), no será auténtica participación sino aquella donde los ciudadanos compartan un poder delegado para adoptar decisiones colectivas que les afectan.

La Participación Real Aparente queda develada cuando los actores sociales generan nuevos espacios y mecanismos para pedir o exigir solución a sus necesidades. Aparece cuando sienten que no son escuchados, tienen la percepción de no poder conseguir lo que quieren a partir de la participación decorativa ni la simbólica o que las instituciones dirigidas por funcionarios públicos, a quienes catalogan como políticos identificados plenamente con el partido de gobierno, no les dan respuestas oportunas:

... a veces no dan respuestas a nuestros problemas, y nos asiste el derecho a nosotros de pelear, para buscar solución a los problemas, a protestar, a insultar, porque puedo usar la radio para decir y denunciar a esos políticos que no hacen nada por la comunidad y eso es estar participando, además eso es parte de la política de echarles a esos políticos chavistas.

En el mismo sentido, otro informante manifestó:

Todo se pinta muy bello... en la constitución está plasmada la participación como muy bella. Ahora, esto en sí no se está llevando a cabo, porque entonces cuando uno va a la práctica, éste, todavía eso no se ha implementado, porque nosotros tenemos que... nosotros vamos a las instituciones, a las del gobierno a reclamar y hasta rogar por solución de parte de ellos, que busquen solucionar nuestros problemas y siempre es lo mismo, no vemos que se le dé solución a los problemas. 
Participar para denunciar o insultar ante los medios es un acto real, pero participar en la gestión pública no es simplemente emitir juicios o realizar pedidos individuales. Para que sea una participación auténtica debe convertirse en la expresión organizada y colectiva de ideales y reivindicaciones que los actores sociales buscan implementar a través de mecanismos institucionales.

Cuando la participación se reduce a "echarle a esos políticos chavistas", es una participación real aparente porque aunque existe una decisión de querer hacer, de no quedarse en el pensamiento, en el deseo, sino pasar al accionar, los actores sociales no atinan los medios necesarios para producirla en forma auténtica y de allí que muchos la perciban muy bella en la teoría pero no en la práctica.

Se puede resumir entonces que las autoridades de las instituciones públicas y sus actuaciones político partidistas dentro de las organizaciones que dirigen impulsan prácticas participativas simuladas en donde solo implican a los colectivos afectos al partido de gobierno, tal como señala un informante: "los que han llegado son los de las misiones y esos son la gente chavista de la directora que viene a apoyarla". Podemos decir que para gran parte de los actores sociales el fomento de la participación ciudadana bajo estas formas enmascaradas conlleva al desencanto hacia la misma por las relaciones de subordinación que genera en ellos ante la autoridad y la perciben como un instrumento de poder de las autoridades para lograr legitimar sus decisiones.

También Ruano (2010) encontró que aun cuando los gobiernos locales españoles han puesto en marcha numerosas iniciativas en materia de participación ciudadana, los representantes políticos las aprovechan como instrumentos de legitimación sin que se traduzcan en iniciativas para la transferencia real de poder al ciudadano.

Algunos actores de este estudio, por otra parte, manifiestan participar en los eventos a que son convocados sin tener un involucramiento real y voluntario sino obligatorio, por temor a sufrir las consecuencias si no dan apoyo a las decisiones tomadas por la autoridad. No obstante, otros tienen la ilusión de estar participando por el solo hecho de recibir invitación y estar presentes en los eventos apoyando a las autoridades.

Por ello, resulta necesario distinguir en el espacio municipal entre esos procesos de participación simulada, donde las decisiones se mantienen en el ámbito gubernamental, ya que desde cargos de autoridad se busca mantener controlados todos los instrumentos de participación para sostener a ultranza el poder político, de aquellos procesos de auténtica participación ciudadana, donde las posibilidades de decidir están en los afectados.

La participación auténtica es definida por King, Feltey y Susel (1998) como la caracterizada, entre otros rasgos, por un estilo de interacción colaborativo y de confianza, con un proceso administrativo visible, abierto y dinámico, en que la participación es buscada incluso antes de que la agenda haya sido establecida, el ciudadano es considerado un socio y no un participante desigual y la decisión surge como resultado de la deliberación, con igual oportunidad para todos de entrar en ese proceso e influir en el resultado.

\subsection{Significado y sentido de la participación ciudadana}

En la cotidianidad de las organizaciones estudiadas, la mayoría de los actores sociales definen que un ciudadano es una persona que tiene derechos y deberes, entre ellos a la participación y, sin embargo, no se muestran seguros en cuanto a su ejercicio: "todo se 
pinta muy bello en la constitución, donde nosotros... jugaremos un papel muy importante en la comunidad".

La caracterización de la participación ciudadana que hicimos en la sección anterior ahora será presentada a través de una escalera en la que se visualiza la Participación Simulada que se actúa en cuatro versiones y las dimensiones con que se manifiestan en el ámbito municipal, a partir de la cual se pueden inferir los significados construidos y sentidos atribuidos a la participación ciudadana por dos clases de actores sociales: los que ostentan cargos de autoridad y poder (AP) y los que se sitúan bajo su conducción o ciudadanía clientelizada $(\mathrm{CC})$.

La figura 2 muestra la Escalera de Participación Simulada como viene gestándose bajo la acción de dos agentes educativos en el espacio municipal. Su estructura está basada en los modelos de Arnstein (1969), Jiménez (2004) y Fawaz y Vallejo (2008). A diferencia de los autores citados, quienes plantean cada peldaño de la escalera de la participación como un tipo distinto que en conjunto representan una secuencia progresiva de desarrollo, en la Participación Simulada los peldaños representan versiones de un mismo tipo y los actores pueden actuar varias de ellas o bien pasar de una dimensión a otra de acuerdo a las circunstancias o situaciones en que participan. En lo que sí coincidimos es en que cada peldaño representa un distinto nivel de efectividad, pero en la Participación Simulada en ninguna de sus versiones se consolida el poder ciudadano.

En los peldaños 1 al 7 de la escalera presentamos un recorrido por las versiones de la Participación Simulada: Clientelar, Decorativa, Simbólica y Real Aparente. En los dos primeros situamos las dimensiones de la Participación Clientelar: la coaccionada y la condicionada, que logra alcanzar un cierto nivel de movilización, esto es, que actores $(\mathrm{CC})$ seleccionados (por AP) asistan a eventos que simulan participación ciudadana pero sin voz más que para repetir consignas, slogans y canciones que son parte de la comunicación mediática.

De allí podemos inferir que, para ambos tipos de actores, la participación ciudadana significa acto de presencia. Sin embargo, el sentido es distinto para cada uno: mientras para AP la presencia de CC es muestra de apoyo y lealtad política, para este último su presencia sirve bien para ganar acceso a bienes, servicios y prebendas o para conservarlos. Los dos primeros peldaños, en donde se circunscribe la coacción y la condición, refieren al nivel de movilización.

En los peldaños 3 y 4 situamos las dimensiones de la Participación Decorativa: la informativa y la consultiva, de acuerdo a la figura legal que le da nombre y con lo cual logra alcanzar un cierto nivel de formalismo. Esto es, cumplir el requisito de que un determinado número de $\mathrm{CC}$, seleccionados por AP, legitimen ciertas actuaciones de la gestión pública. 


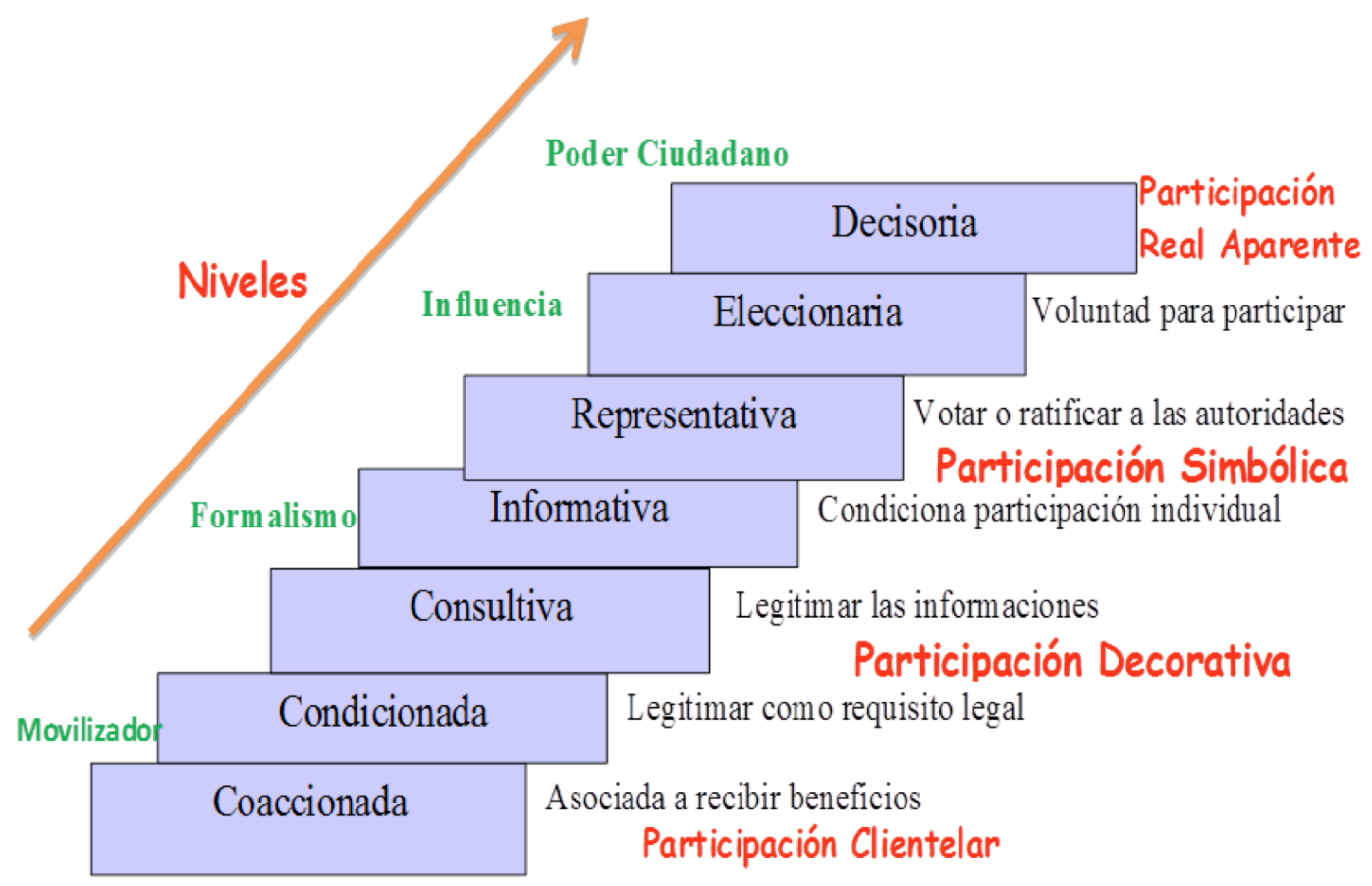

Asociada a no perder beneficios

Figura 2. Escalera de la participación simulada

Fuente: Elaboración propia.

Observamos que, aunque se logre otro nivel, el formalismo, el significado de la participación ciudadana sigue siendo el mismo que en el nivel anterior: acto de presencia. Su sentido es distinto pero igual para ambos tipos de actores: legitimación. Así, la participación decorativa en sus dos dimensiones se manifiesta en las estructuras formales de participación, asambleas y consultas públicas, donde igual que en el nivel anterior, asiste un cierto número de actores pero sin voz, de modo que la información se da de manera unilateral y la consulta no se hace.

Los peldaños 5 y 6 corresponden a dos dimensiones, representativa y eleccionaria, de la Participación Simbólica, que logra alcanzar un cierto nivel de influencia ya que, con sus firmas y/o huellas, la presencia de los CC queda registrada en la estructura legal de la gestión pública. Tan solo las firmas y/o huellas simbolizan la voz de los participantes y, en otros casos, lo acompaña la mano alzada. De allí podemos inferir que, para ambos tipos de actores, la participación ciudadana significa voz y voto pero mientras para AP ello tiene un sentido de legalización, para CC su sentido es el de figurar.

El último peldaño, el 7, corresponde a un nivel de poder ciudadano no consolidado. Se trata de una Participación Real Aparente ya que, aun cuando CC hace uso de medios que la democracia ofrece - distintos a los del nivel anterior porque no son instrumentados por AP- para que su voz sea oída, esta no cuestiona el régimen tal como se desarrolla sino que solo reclama el incumplimiento de lo ofrecido por parte de AP. En este caso, el significado que CC ha construido de la participación ciudadana es intervención en la gestión pública con voz pero en el sentido de satisfacer un interés particular, no público. Por expresiones públicas escuchadas reiterativamente en medios de comunicación, podemos inferir que para AP el sentido de tal modo de participación ciudadana es el saboteo. 
Sin dudar que hay actores cuya formación les permita entender el significado de la participación ciudadana contenido en la Constitución, tales actores no se hacen visibles en el espacio municipal en un ejercicio ciudadano relevante. No obstante, es importante destacar otros significados de la participación ciudadana recogidos en la indagación, manifestados por actores que no encajan en la categoría ciudadanía clientelizada, mucho menos se ubican en posiciones de autoridad. Así se tiene que, para algunos actores, la participación ciudadana es cumplir con el deber, es decir, esta participación significa desempeñar voluntariamente unas funciones en la gestión de lo común, cuando señalan "por eso digo que uno tiene que cumplir con los deberes, con tus responsabilidades que se tienen como ciudadanos que somos, metiéndonos en todo lo que podamos en la comunidad, bueno, en todo lo que ocurre a diario".

Otro significado es trabajo colectivo, que se evidencia cuando dicen "trabajar pero claro no solo, sino todos juntos, todo el grupo y en la comunidad", de lo que podemos inferir que perciben la organización comunitaria como un componente primordial de la participación ciudadana. Asociado a lo anterior, encontramos otro significado, más cercano a su acepción política, involucramiento en las decisiones sobre aspectos de interés común: "Uno como integrante de una comunidad debe tener derecho a actuar tanto en el bienestar como en las decisiones que se vayan a tomar". Y aún, para otros actores, la participación ciudadana significa libertad de expresión, cuando la asocian a "la libertad que tiene cada ciudadano para expresar sin ataduras lo que piensa sobre algún problema específico".

Podemos observar que a tales significados de la participación ciudadana los actores sociales les atribuyen un sentido de solución de problemas: "es a través de ella que podemos hacer fuerza para buscar soluciones”. Es decir, que esos significados están más cerca al de participación comunitaria que a la ciudadana, con lo que estos actores, al participar, pueden tener la sensación de estar empoderados de la participación instituida en la Constitución sin advertir que con tal instrumentalización de la participación se corre el riesgo de desactivarla porque eventualmente, al cesar el problema, dejarán de participar.

Los hallazgos anteriores nos permiten inferir que los diversos significados construidos y sentidos atribuidos a la participación ciudadana por los actores sociales devienen de las experiencias concretas que han vivenciado. En ello concuerdan Pino y Colino (ob. cit.), quienes reportan una gran variedad de significados de la participación ciudadana en las diferentes experiencias que estudiaron: para algunos, la participación es el simple intercambio de información, ascendente o descendente, o cualquier consulta de los ciudadanos; para otros no se puede hablar de tal sin la concertación y el diálogo, o la cogestión o co-producción de los servicios; para otros, por último, las iniciativas de participación son simple política de imagen y legitimación de la acción política.

\section{A modo de cierre}

Indudablemente la participación ciudadana en Venezuela a nivel municipal ha ganado espacios pero su actuación, asociada a prácticas clientelares que constituyen las posibilidades ofrecidas a los actores para mejorar su calidad de vida, vulneran la esencia política de la participación ciudadana. En tales escenarios, los significados construidos y sentidos atribuidos por los actores a su participación en lo público dan cuenta de una 
formación ciudadana débil, instrumental a los fines de los poderes políticos dominantes que mantienen a un gran número de la población sumisa y a otra, resignada.

Se tiene entonces una gestión pública que tiene el mandato de convertir al Estado y sus instituciones en instrumentos amplios para la formación de ciudadanía democrática y, sin embargo, todavía no responden a las nuevas exigencias que demanda la normativa jurídica referida a configurar una cultura política participativa. Una gestión pública realizada por actores que, queremos creer, no tienen conciencia de que sus actuaciones modelan la formación de ciudadanía. Todavía existen muchas dificultades para que los ciudadanos aprendan y se empoderen de la participación, en primer lugar, porque son pocos los espacios en los que pueden tener acceso a la toma de decisiones y, en segundo lugar, se acrecienta el elemento de la partidización en la gestión, lo que desdibuja las posibilidades de una participación protagónica.

No se afirma con lo anterior que la participación per se genere actitudes ciudadanas. Muchas veces, al abrirse los espacios e integrarse los ciudadanos, lamentablemente se reproducen actitudes autoritarias, redes clientelares y se busca el interés particular. A todo ello se suma el poco sentido de comunidad que aún se evidencia en que las personas siguen pensando, seguramente por la infinidad de carencias con que viven, más en su propio beneficio que en el bien común.

Las actitudes ciudadanas se generan en un contexto socio político que las cultiva, de allí la importancia de las instituciones como agentes educativos. El Concejo Municipal y la escuela son entendidos como escenarios de la participación ciudadana, pero en ningún caso son percibidos como agentes dinámicos con capacidad para garantizar las condiciones para institucionalizar una participación más cónsona con criterios de justicia, ni tampoco como instrumento de formación de ciudadanía.

\section{Referencias}

Arnstein, S. R. (1969). A ladder of citizen participation. JAIP, 35(4), 216-224. Recuperado de http://lithgow-schmidt.dk/

Audelo, J. (2004). ¿Qué es clientelismo? Algunas claves para comprender la política en los países en vías de consolidación democrática. Estudios Sociales, 27(24), 124-142.

Ballester, B. (2006). Reconocimiento del otro. Democracia participativa en la gestión escolar. Tesis doctoral. Universidad Nacional Experimental Simón Rodríguez, Caracas.

Barrera, A. (2004). Innovación política y participación ciudadana. El sistema de gestión participativa del distrito metropolitano de Quito. Buenos Aires: CLACSO.

Beltrán, F. (1998). La inevitable necesidad de la participación en la escuela pública. Revista Enfoques Educacionales, 1(2), 25-49.

Cabezudo, A. (diciembre, 2006). Ciudad educadora, una manera de aprender a vivir juntos. Ponencia presentada en el III Congreso de Educación para el Desarrollo. La educación transformadora ante los desafíos de la globalización. Universidad del País Vasco, Vitoria-Gasteiz.

Cantón, V. Aguirre, M. y Castro, Y. (1999). Formación cívica y ética. De libertades y repúblicas. Ciudad de México: Limusa.

Carranza, M., Garriga, H. y Llinás, M. (2011). Saltamos a la ciudad. Siete propuestas para vivir la educación física fuera de la escuela. Barcelona: Graó. 
Cernadas, A., Pineda, C. y Chao, L. (2013). Democracia local y participación ciudadana. Estudio comparativo de Galicia y La Rioja. RIPS, 12(1), 175-209.

Coma, L. (2011). Actividades educativas y didáctica del patrimonio en las ciudades españolas. Análisis, estado de la cuestión y valoración para una propuesta de modelización. Tesis doctoral. Universitat de Barcelona, Barcelona.

De Alba, N., García, F. y Santisteban, A. (2012). Educar para la participación ciudadana en la enseñanza de las ciencias sociales. Sevilla: Díada Editora.

Fawaz, J. y Vallejos, R. (2008). Construyendo participación ciudadana a nivel local. La experiencia de los pequeños productores agropecuarios de la provincia de Ñuble. Teoría, $17(1)$, 19-32.

Folgueiras, P. (2005). De la tolerancia al reconocimiento: programa de formación de ciudadanía intercultural. Tesis doctoral. Universitat de Barcelona, Barcelona.

Fuenmayor, L. (2006). Ética para la reflexión política. Dos ensayos para la acción. Barquisimeto: Ediciones del Rectorado UCLA.

García, J. y García, A. (1996.) Teoría de la educación. Educación y acción pedagógica. Salamanca: Ediciones Universidad de Salamanca.

Glaser, B. y Strauss, A. (1967). The discovery of grounded theory. Chicago, IL: Aldine.

González, A. (2011). Los desafíos de la participación ciudadana local. Un estudio comparado entre las ciudades de Madrid y Helsinki. Reforma y Democracia, 49, 1-19.

Gunes-Ayata, A. (1997). Clientelismo: Premoderno, moderno, posmoderno. En J. Auyero (Comp.), ¿Favores por votos? Estudios sobre clientelismo político contemporáneo (pp. 19-26). Buenos Aires: Losada.

Jiménez, M. (2004). Participación a nivel local. Recuperado de http://www.subdere.gov.cl/1510/article-65917.html

King, C., Feltey, K. y Susel. B. (1989). The question of participation: toward authentic public participation in public administration. Public Administration Review, 58(4), 317-326.

Landini, F. (2012). Prácticas clientelares y control político en la experiencia campesina de Argentina. Perfiles Latinoamericanos, 40, 205-226.

Pino, E. y Colino, C. (2007). Un fantasma recorre Europa: renovación democrática mediante iniciativas de promoción de la participación ciudadana en los gobiernos locales (Alemania, Francia, Reino Unido y España). Recuperado de http://digital.csic.es/handle/10261/1681

Rebollo, O. (2004). La ciudad educadora y la participación ciudadana. Ánfora, 14(22), 96-108.

Román, L. (2012). Consecuencias políticas de la acción administrativa: el paradigma del ciudadanocliente. RIPS, 11(1), 81-103.

Roser, B. (2006). Los proyectos educativos de ciudad. Gestión estratégica de las políticas educativas locales. Buenos Aires: CIDEU.

Ruano, J. (2010). Contra la participación: discurso y realidad de las experiencias de participación ciudadana. Política y Sociedad, 47(3), 93-108.

Sánchez, I. (2006). Educación para una ciudadanía democrática e intercultural. Tesis doctoral. Universitat de Barcelona, Barcelona.

Sirvent, M. (1999). Cultura popular y participación social. Una investigación en el barrio de Mataderos. Buenos Aires: Miño y Dávila Editores.

Weber, M. (1973). Ensayos sobre metodología sociológica. Buenos Aires: Amorrortu. 


\section{Breve CV de las autoras}

\section{Judith Rojas de Lúquez}

Candidata a Doctora en Ciencias de la Educación por la Universidad Latinoamericana y del Caribe (ULAC), sede Caracas. Profesora de Biología Universidad Experimental Pedagógica Libertador, Instituto Pedagógico de Barquisimeto (UPEL-IPB). Especialista y Magister en Gerencia Educativa UPEL-IPB. Se ha desempeñado como profesora y como directora en planteles de Educación Inicial y Media Diversificada y Profesional, supervisora y coordinadora de Asuntos Administrativos de la Dirección de Educación del Municipio Torres del Estado Lara, coordinadora de la Jefatura de Trámite Docente de la Zona Educativa del Estado Lara. Concejal del ente Legislativo del Municipio Torres, estado Lara (2005-2013). Actualmente docente invitada del Posgrado de la Universidad Nacional Experimental Rafael María Baralt y miembro activo de la Línea de Investigación Aprendizaje Organizacional, UNESR, Núcleo Barquisimeto. Email: judithdlu@hotmail.com

\section{Belkis Ballester Pérez}

Doctora en Ciencias de la Educación por la Universidad Nacional Experimental Simón Rodríguez (UNESR). Graduada como Maestra Especialista en Niños con Dificultades de Aprendizaje en IUAVEPANE, obtuvo el Bachelor y Master in Education (Special) por la Sonoma State University, California, USA. Se ha desempeñado como profesora y coordinadora de la Maestría en Ciencias de la Educación y responsable del área Comportamiento de Organizaciones Educativas del Doctorado en Ciencias de la Educación, ambas de la UNESR, Núcleo Barquisimeto. Ha facilitado cursos y seminarios de investigación en los doctorados de varias universidades nacionales (UPEL, UNEFA, ULAC). Fundadora e investigadora activa de la Línea de Investigación Aprendizaje Organizacional, UNESR, Núcleo Barquisimeto y miembro invitada de la Línea Educación, Democracia y Ciudadanía, UNESR, Núcleo de Postgrado, Caracas. Miembro de AsoVAC y de RINACE. Investigadora Acreditada FONACIT.Email: belkisb12@gmail.com 